\title{
Review
}

\section{Molecular phylogeny among Triticum-Aegilops species and of the tribe Triticeae}

\author{
Taihachi Kawahara* \\ Plant Germ-plasm Institute, Graduate School of Agriculture, Kyoto University, Muko 617-0001, Japan
}

\begin{abstract}
The tribe Triticeae includes some of the world's most important cereal crops, such as wheat, barley, and rye. It also includes important, mostly perennial, fodder grasses such as Agropyron, Elymus, Leymus, Psathyrostachys, and others. Many wild annual grasses of the tribe Triticeae belong to a highly valuable gene pool for cereal breeding - Triticum, Aegilops, Secale, Hordeum, Dasypyrum, etc., and some are interesting ephemeral plants of deserts, including Eremopyrum, Crithopsis, and Heteranthelium. Another group is interesting taxonomically, because they are on the border or just beyond the limit of the tribe, such as Brachypodium and Henrardia. Triticeae is a taxonomically controversial group at both the species and generic level. One extreme is considering Triticum to be the only genus of Triticeae, and an opposite extreme is accepting of a huge amount of often monotypic genera. Therefore, it seemed appropriate to review here several issues of the taxonomy and phylogeny of the tribe Triticeae.
\end{abstract}

Key Words: Molecular phylogeny, Triticum-Aegilops complex, Triticeae, monophyly.

\section{Introduction}

This special issue of Breeding Science, Japanese Society of Breeding, constitutes the proceeding of the 6th International Triticeae Symposium, which was held in Kyoto, Japan, from 31 May to 5 June 2009. The previous symposia were held in Helsingborg, Sweden (1991), Logan, Utah, U.S.A. (1994), Aleppo, Syria (1997), Cordoba, Spain (2001), and Prague, Czech Republic (2005). Like its predecessors, the Sixth Symposium brought together individuals in many different disciplines who have in common their interest in one group of grasses, the Triticeae (Kawahara 2009).

The tribe Triticeae includes several of the world's most important cereal crops, such as wheat, barley, triticale, and rye. It also includes important, mostly perennial, fodder grasses such as Agropyron, Elymus, Leymus, Psathyrostachys, and others. Many wild annual grasses of the tribe Triticeae belong to a highly valuable gene pool for cereal breeding, including Triticum, Aegilops, Secale, Hordeum, Dasypyrum, etc., and some are interesting ephemeral plants from desert environments, such as Eremopyrum, Crithopsis, and Heteranthelium. Another group is interesting taxonomically, because they are on the border or just beyond the limit of the tribe, namely Brachypodium and Henrardia. Triticeae grasses are distributed worldwide; however, their center of diversity is in the temperate belt of Eurasia, North America, and South America. They are important, dominant, or the

Communicated by M. Iwanaga

Received September 4, 2009. Accepted September 28, 2009.

*Corresponding author (e-mail: kawatai@mbox.kudpc.kyoto-u.ac.jp) only plants in several habitats and accompany humans as weeds. They all possess a tremendous richness of genes and gene complexes useful in agricultural research and breeding. The tribe Triticeae is a taxonomically controversial group at both the species and generic level. One extreme is considering Triticum to be the only genus of the Triticeae (Stebbins 1956), and an opposite extreme is accepting of a huge amount of often monotypic genera (Dewey 1984, Löve 1984). On the other hand, common wheat, Triticum aestivum L., has been the textbook example of evolution by allopolyploid formation (Kihara 1954). Hence, recent studies on molecular phylogeny of the tribe Triticeae are reviewed here with special emphasis on the Triticum-Aegilops complex, which has a very long history of evolutionary studies.

\section{Current taxonomic status of Triticum-Aegilops com- plex and the tribe Triticeae}

The tribe Triticeae is a fairly big group of grasses with 330 (Clayton and Renvoize 1986) to 360 (Watson and Dallwitz 1994) species, in which the genus Elymus (ca. 150 species) is the largest and most widely distributed. After the finding of a polyploid series in wheat by Sakamura (1918), Kihara started genome analysis in wheat and its wild relative Aegilops (Kihara 1954, Lilienfeld 1951). Genome analysis has proved its effectiveness in unraveling genomic and phylogenetic relationships in the Triticum-Aegilops complex and was applied to other genera of the Triticeae (von Bothmer 1995, Wang et al. 1994). These methods were employed first to examine the phylogenetic relationships of Hordeum and Secale, two important crops of the Triticeae, and then other 
perennial genuses, such as Elymus. Based on the accumulated information on these genomes, Dewey and Löve independently proposed that generic classification in the Triticeae should be based on the genomic constitution of each species just a quarter century ago (Dewey 1984, Löve 1984). Their proposal has been widely accepted by many researchers, especially those who deal with perennial species such as Elymus (e.g. Mason-Gamer et al. 2005, Sun and Salomon 2009) as well as most taxonomists (for reviews, Barkworth and von Bothmer 2005, 2009, Yen and Yang 2009, see also Table 1).

On the other hand, support for the proposals of Dewey and Löve has not forthcoming from those who deal with annual group. Löve's idea to split Aegilops by their genomic constitution was generally rejected and the genus retained its previous status as treated by Linnaeus. The opposite proposal to merge Aegilops into Triticum (Bowden 1959, Yen and Yang 2009) also failed to receive widespread acceptance. The Triticum-Aegilops complex is a small group in the Triticeae with ca. 28 species, but its economic importance is very large and most wheat geneticists and breeders prefer to retain the familiar names of Aegilops and Triticum. In this context, Clayton and Renvoize (1986) wrote, "Bearing in mind the genetic constitution of $T$. aestivum, its separation from Aegilops is a matter of some contention." Similarly, Löve's separation of Critesion Raffin. with the $\mathrm{H}$ genome from Hordeum L. with the I genome also failed to find acceptance, and many researchers (e.g. Kakeda et al. 2009, Peterson and Seberg 2009, Taketa et al. 2009) continue to use Hordeum s.l. Yen and Yang (2009) proposed retaining Hordeum but used genomic constitutions to separate sections within the genus. Clear morphological uniformity of Hordeum with triads of one central spikelet and two laterals in fragile rachis may help to retain this familiar name.

\section{Molecular phylogeny of diploid Triticeae}

In the past 15 years, the tribe Triticeae has been the focus of numerous molecular phylogenetic studies based on data from chloroplast DNA markers, high-copy nuclear genes, and low or single-copy nuclear genes. Some of the earlier studies showed conflict with one another due to past hybridization among genera, possible introgression, limited taxon sampling, or a combination of these. For example, although some molecular studies showed that Aegilops and Triticum form a monophyletic clade (Hsiao et al. 1995, Huang et al. 2002a, 2002b, Kellog and Appels 1995, Kellog et al. 1996, Mason-Gamer et al. 1998, 2002), many other molecular and morphological studies revealed polyphyly of the TriticumAegilops complex (Mason-Gamer 2001, 2004, 2005, Peterson and Seberg 1997, Sallares and Brown 2004, Seberg and Frederikson 2001). To reduce the effect of past hybridization among genera, it is necessary to construct a robust phylogeny among diploid genomes first, as well as clarifying species relationships among diploids and polyploids. Yamane and Kawahara (2005) analyzing base-pair substitutions,
Table 1. Genera included in tribe Triticeae in recent monographs on Grasses

Clayton and Renvoize (1986)

Aegilops, Agropyron, Brachypodium, Crithopsis, Dasypyrum, Eremopyrum, Elymus, Henrardia, Heteranthelium, Hordelymus, Hordeum, Hystrix, Leymus, Psathyrostachys, Secale, Sitanion, Taeniatherum, Triticum

Watson and Dallwiz (1994) ${ }^{a}$

Aegilops, Agropyron, Amblyopyrum, Australopyrum, Cockaynea, Crithopsis, Dasypyrum, Elymus, Elytrigia, Eremopyrum, Festucopsis, Henrardia, Heteranthelium, Hordelymus, Hordeum, Hystrix, Kengyilia, Leymus, Lophopyrum, Malacurus, Pascopyrum, Peridictyon, Psathyrostachys, Pseudoroegeneria, Secale, Sitanion, Taeniatherum, Thinopyrum, Triticum

a Brachypodium is placed in the separate monogeneric tribe Brachypodieae.

indels, and microsatellites in chloroplast noncoding regions in all diploid Triticum-Aegilops species, revealed the polyphyletic nature of the Triticum-Aegilops clade. Their data showed that Aegilops speltoides Tausch is the sister group to the remaining species of the Triticum-Aegilops complex, including Ae. mutica Boiss. (Amblyopyrum muticum), and the latter included the Secale branch containing crossfertilizing Secale cereale L. and self-fertilizing S. sylvestre Host.

Peterson et al. (2006) also confirmed this basal position of Ae. speltoides based on the sequence data of two nuclear genes, DMC1 and EF-G, and a plastid gene, $n d h \mathrm{~F}$. They further revealed that as many as 14 other Triticeae genera formed a clade together with Triticum-Aegilops that is the sister to Ae. speltoides and the B genome of polyploid wheat. The 14 Triticeae genera were Agropyron, Australopyrum, Crithopsis, Dasypyrum, Eremopyrum, Festucopsis, Heterantherium, Hordeum, Lophopyrum, Peridictyon, Psasyrostachys, Secale, Taeniatherum, and Thinopyrum (Peterson et al. 2006). Another sister clade contained only two genera, Henrardia and Pseudoroegeneria. Because they selected representatives of all the genomes traditionally recognized in diploid Triticeae, there is no problem in taxon sampling. On the other hand, the possible effect of past hybridization among genera and/or possible introgression cannot be ruled out because they used two nuclear genes. Their phylogenetic tree based on the plastid gene $n d h \mathrm{~F}$ showed that only three genera, Crithopsis, Secale, and Taeniatherum, has the possibility to be included within Ae. speltoides plus the other Triticum-Aegilops clade (Peterson et al. 2006). Crithopsis, Secale, and Taeniatherum again formed a cluster together with Aegilops (and Ambryopyrum) and Triticum in the phylogenetic tree based on plastid $R b c \mathrm{~L}$ and $n d h \mathrm{~F}$ in a recent study (Peterson and Seberg 2008). These studies apparently showed polyphyly of the Triticum-Aegilops complex where Ae. speltoides formed a distinct clade. They further suggested that several Triticeae genera, at lease Secale, will be included in between 
Ae. speltoides and the Triticum-Aegilops clade.

The genus Hordeum is another group with abundant information on its molecular phylogeny, but such a polyphyletic relationship has not yet been reported (Baum and Johnson 2007, Blattner 2004, Kakeda et al. 2009, Komatsuda et al. 2001, Nishikawa et al. 2002, Sun et al. 2009, Peterson and Seberg 2003, 2009, Taketa et al. 2009). Because most of these studies focused on the phylogenetic relationships among diploid, tetraploid, and hexaploid species, only one or two accessions belonging to other Triticeae genera were employed as outgroups. All four phylogenetic trees constructed by Peterson et al. (2006) strongly suggested a monophyletic status of Hordeum, but more studies will be necessary to confirm this.

\section{Genetic background that control spike morphology}

Yamane and Kawahara (2005) also pointed out the terminal position of Ae. mutica together with Ae. umbellulata Zhuk. within the Triticum-Aegilops clade. Some molecular analyses also suggested that Ae. mutica is close to Ae. umbellulata (Terachi et al. 1984, Murai et al. 1989) as well as to Ae. caudata L., Ae. comosa Sm. in Sibth. \& Sm., Ae. umbellulata, Ae. uniaristata Vis. (Dvořák and Zhang 1992), and Ae tauschii Coss. (Terachi and Tsunewaki 1992). This poses a discrepancy between molecular phylogeny and classification based on morphology. Based on several morphological characters (e.g., awnless linear spikes) that differentiate Ae. mutica from other Aegilops species, van Slageren (1994) claimed that Ae. mutica should belong to genus Amblyopyrum instead of genus Aegilops. Ae. mutica and Ae. speltoides are the only predominantly cross-pollinating diploid species in the genus. Because most perennial relatives in the tribe Triticeae are allogamous, allogamy is generally accepted as an ancestral character. In addition, Ae. mutica bears a close resemblance to the perennial relatives, especially Agropyron, so it has been considered an ancestral species based on morphological and cytogenetic analyses (reviewed by Ohta 1991). Ae. mutica and Ae. umbellulata have quite different morphological characteristics, as shown in Table 2. If the two species differentiated rather recently, it is highly possible that few genes or a few tightly linked clusters of genes control these characteristics. A similar situation is also found in Secale. Secale has linear membranous glumes but Aegilops and Triticum (and also other genus such as Elymus) has oblong to ovate glumes.

Zohary and Imber (1963) and Wains et al. (1979) pointed out that drastic morphological change in spike shape could be caused by a block of closely linked genes. Ae. speltoides has two varieties, var. speltoides with narrow cylindrical, 7$15(-20) \mathrm{cm}$ long spikes, awnless lateral spikelets, disarticulating usually at the bottom of the spike and var. ligustica with distichous, narrow cylindrical, 7-10 cm long spikes, awned lateral spikelets disarticulating wedge-type (spike axis attaching to below spikelets) at maturity, with the ligustica characters dominant over the speltoides ones. Similarly, when hybrids were made between Ae. longissima Scwinf. et Muschl. without lateral awn and disarticulation at the bottom of the spike and Ae. bicornis (Forsk.) Jaub. et Sp. with lateral awns and wedge-type disarticulation, the Ae. bicornis disarticulation character was dominant over the intact rachis of Ae. longissima (Waines et al. 1979). In the $\mathrm{F}_{2}$ generation of hybrids between Ae. longissima and Ae. bicornis, a 3:1 segregation for spike shattering was observed, suggesting that the Ae. bicornis wedge-type disarticulation character is controlled by one gene or one block of linked genes. Such a drastic morphological change in spike character caused by one mutation was also reported in Hordeum. It is well known that six-rowed cultivated barley with the vrs 1 gene originated with a mutation from two-rowed barley with Vrsl. This $V r s 1$ gene was recently characterized and loss of function leads to conversion of the rudimentary spikelets of two-rowed barley into the fertile spikelets of six-rowed barley (Komatsuda et al. 2007). Because the genus Hordeum has three spikelets at each rachis node, $V r s 1$ is apparently one of the genes that regulate the development of lateral spikelets and cause morphological changes in the spikes. The number of spikelets at each rachis node is sometimes considered significant in generic circumscription in Triticeae, but one or a few genes may control this. If linear membranous glumes of Secale can change to oblong to ovate glumes of Triticum-Aegilops complex or vice versa by a single mutation, inclusion of Secale in between the Ae. speltoides clade and the other Triticum-Aegilops clade will be explained by this single mutation. Similarly, drastic morphological differences between Ae. umbellulata and

Table 2. Differences in morphological characteristics between Aegilops mutica and Ae. umbellulata

\begin{tabular}{lll}
\hline \hline Character & Ae. mutica & Ae. unbellulata \\
\hline Shape of spike & Very long, linear & Short, ovate, the upper markedly smaller \\
No. of spikelets & Many & Few, usually only 1-2 well developed \\
No. of fertile florets & $3-4$, rarely 5 & Usually 2 \\
Glume awn & No & $3-5$ awned \\
Lemma awn & No & $2-3$ awned \\
Pollination & Predominantly cross-pollination & Self-pollination possible \\
Seed set by bagging & No & Yes \\
Disarticulation & At the base of spikelets or florets, when rachis disarticulate & At the base of spike, spike intact
\end{tabular}


Ae. mutica (Table 2) in spite of their supposed close phylogenetic relationship may be explained by a single gene or a closely linked block of genes.

\section{Outlook and conclusions}

The papers by Dewey and Löve have encouraged genomic studies and discussions on generic definitions within the tribe Triticeae. Although their proposal to define genera by their genomic constitution has not been accepted in several genera, many research paper have provided information on the genomic constitution of the species involved. Genome analysis based on morphological, cytological, and molecular information has been a very powerful tool in phylogenetic studies, including tetraploid and hexaploid species. Ellneskog-Staam et al. (2007) proposed to place Leymus-like species of Hystrix into Leymus and Elymus-like ones into Elymus, respectively, based on genomic analysis by GISH (genomic in situ hybridization) and Southern genomic hybridization. Although such taxonomic rearrangements will continue, we need to clarify the phylogenetic relationships of this tribe as a whole to integrate information on the individual genomes at the same time. The first step will be to construct a robust phylogenetic tree of all the diploid genomes in the tribe Triticeae.

Through advances in Triticeae genomics (e.g. Stein 2007), many Triticeae gene loci have been sequenced and characterized. Some of these are responsible for spike morphology or grain characteristics, $Q$ of $T$. aestivum (Faris et al. 2003), Ha (Hardness) of Triticum and Aegilops (Chantret et al. 2005), Vrsl of H. vulgare L. (Komatsuda et al. 2007), and Nud of H. vulgare (Taketa et al. 2008). $Q$ is thought to be a major regulatory gene for floral development (Muramatsu 1986), and Chantret et al. (2005) proposed an APETALA2 ( $A P 2$ )-like gene as a candidate for $Q$ gene because $A P 2$ is known to play a major role in controlling floral homeotic gene expression. This was also confirmed by Simons et al. (2006). A wide array of molecular techniques has allowed us to understand the genetic basis of other important traits. We can also hope that such progress will enable us to understand why differences in genomes result in different morphologies.

When using the tribe Triticeae as a gene pool for breeding of indispensable cereals, we must view the tribe from biodiversity and conservation angles as well (e.g. Holubec 2005, Knüpffer 2009). Species identification is an urgent problem, not only for the practical utilization of genetic resources but also in understanding the whole evolutionary history of this tribe. In identifying species, we still need to develop a species-level treatment of the tribe. Barkworth and von Bothmer (2005) proposed an approach to develop illustrated, multi-entry keys using programs such as DELTA (Dallwitz 1980, Dallwitz et al. 1993, 1995, 2000) or Lucid ID (Centre for Bioinformation Technology 2004). Adopting such an approach would undoubtedly facilitate the identification of species of the tribe Triticeae.

\section{Literature Cited}

Barkworth,M.E. and R.von Bothmer (2005) Twenty-one years later: The impact of Löve and Dewey's genomic classification proposal. Czech J. Genet. Plant Breed. 41: 3-9 (Special Issue).

Barkworth,M.E. and R.von Bothmer (2009) Scientific names in the Triticeae. In: Feuillet,C. and G.J.Muehlbauer (eds.) Genetics and Genomics of the Triticeae, Springer, New York, pp.3-30.

Baum,B.R. and D.A.Johnson (2007) The 5S DNA sequences in Hordeum bogdanii and in the H. brevisubulatum complex, and the evolution and the geographic dispersal of the diploid Hordeum species (Triticeae: Poaceae). Genome 50: 1-14.

Blattner,F.R. (2004) Phylogenetic analysis of Hordeum (Poaceae) as inferred by nuclear rDNA ITS sequences. Mol. Phylogenet. Evol. 33: 289-299.

von Bothmer, R., N.Jacobson, C.Baden, R.B.Jorgensen and I.LindeLaurson (1995) An ecogeographical study of the genus Hordeum. 2nd edn. Systematic and Ecogeographical Studies on Crop Genepools 7, IPGRI, Rome.

Bowden,W.M. (1959) The taxonomy and nomenclature of the wheats, barleys and ryes and their wild relatives. Canad. J. Bot. 37: 657684.

Centre for Bioinformation Technology (2004) Lucid ID. University of Queensland, Brisbane, Australia.

Chantret, N., J.Salse, F. Sabot, S.Rahman, A. Bellec, B.Laubin, I. Dubois, C.Dossat, P.Sourdille, P.Joudrier et al. (2005) Molecular basis of evolutionary events that shaped the Hardness locus in diploid and polyploid wheat species (Triticum and Aegilops). The Plant Cell 17: 1033-1045.

Clayton,W.D. and S.A.Renvoize (1986) Genera Graminum: Grasses of the World, Royal Botanic Gardens, Kew, p. 389.

Dallwitz,M.J. (1980) A general system for coding taxonomic descriptions. Taxon 29: 41-46.

Dallwitz,M.J., T.A.Paine and E.J.Zurcher (1993) User's guide to the DELTA system: A general system for processing taxonomic descriptions, 4th ed. http://delta-intkey.com.

Dallwitz,M.J., T.A.Paine and E.J.Zurcher (1995) User's guide to Intkey: A program for interactive identification and information retrieval. http://delta-intkey.com.

Dallwitz,M.J., T.A.Paine and E.J.Zurcher (2000) Principles of interactive keys. http://delta-intkey.com.

Dewey,D.R. (1984) The genomic system of classification as a guide to intergeneric hybridization with the perennial Triticeae. In: Gustafson,J.P. (ed.) Gene manipulation in Plant Improvement, Pleum Publishing, New York, pp. 209-279.

Dvorak, J. and H.B.Zhang (1992) Reconstruction of the phylogeny of the genus Triticum from variation in repeated nucleotide sequences. Theor. Appl. Genet. 84: 419-429.

Ellneskog-Staam, P., R. von Bothmer, K. Anamthawat-Jónsson and B.Salomon (2007) Genome analysis of species in the genus Hystrix (Triticeae; Poaceae). Plant Syst. Evol. 265: 241-249.

Faris, J.D., J.P.Fellers, S.A.Brooks and B.S.Gill (2003) A bacterial artificial chromosome contig spanning the major domestication locus $Q$ in wheat and identification of a candidate gene. Genetics 164: 311-321.

Holubec, V. (2005) Triticeae biodiversity and conservation, a "Genebanker" view. Czech J. Genet. Plant Breed. 41: 118-121 (Special Issue).

Hsiao, C., N.J.Chatterton, K.H.Asay and K.B.Jensen (1995) Phylogenetic relationships of the monogenomic species of the wheat tribe, Triticeae (Poaceae), inferred from nuclear rDNA (internal 
transcribed spacer) sequences. Genome 38: 211-223.

Huang, S., A.Sirikhachornkit, J.D.Faris, X.Su, B.S.Gill, R.Haselkorn and P.Gornicki (2002a) Phylogenetic analysis of the acetyl-CoA carboxylase and 3-phosphoglycerate kinase loci in wheat and other grasses. Plant Mol. Biol. 48: 805-820.

Huang,S., A.Sirikhachornkit, X.Su, J.D.Faris, B.S.Gill, R.Haselkorn and P.Gornicki (2002b) Genes encoding plastid acetyl-CoA carboxylase and 3-phosphoglycerate kinase of the Triticum/Aegilops complex and the evolutionary history of polyploid wheat. Proc. Natl. Acad. Sci. USA 99: 8133-8138.

Kakeda,K., S.Taketa and T.Komatsuda (2009) Molecular phylogeny of the genus Hordeum using thioredoxin-like gene sequences. Breed. Sci. 59: 595-601.

Kawahara,T. (2009) The 6th International Triticeae Symposium (6th ITS). Wheat Inf. Serv. 108: 25-66. www.shigen.nig.ac.jp/ewis.

Kellogg,E.A. and R.Appels (1995) Intraspecific and interspecific variation in 5S RNA genes are decoupled in diploid wheat relatives. Genetics 140: 325-343.

Kellogg,E.A., R.Appels and R.J.Mason-Gamer (1996) When genes tell different stories: the diploid genera of Triticeae (Gramineae). Systematic Botany 21: 1-17.

Kihara,H. (1954) Considerations on the evolution and distribution of Aegilops species based on the analyser-method. Cytologia 19: 336357.

Knüpffer,H. (2009) Triticeae genetic resources in ex situ genebank collections. In: Feuillet,C. and G.J.Muehlbauer (eds.) Genetics and Genomics of the Triticeae, Springer, New York, pp.31-79.

Komatsuda,T., B.Salomon, T.Bryngelsson and R.von Bothmer (2001) Phylogenetic analysis of Hordeum marinum Huds. based on nucleotide sequences linked to the vrs 1 locus. Plant Syst. Evol. 227: 137-144.

Komatsuda,T., M.Pourkheirandish, C.He, P.Azhaguvel, H.Kanamori, D.Perovic, N.Stein, A.Graner, T.Wicker, A.Tagiri et al. (2007) Six-rowed barley originated from a mutation in a homeodomainleucine zipper I-class homeobox gene. Proc. Natl. Acad. Sci. USA 104: 1424-1429.

Lilienfeld,F. (1951) H. Kihara: Genome-analysis in Triticum and Aegilops. X. Concluding review. Cytologia 16: 101-123.

Löve,A. (1984) Conspectus of the Triticeae. Feddes Repertorium 95: 425-521.

Mason-Gamer,R.J., C.F.Weil and E.A.Kellogg (1998) Granule-bound starch synthase: structure, function, and phylogenetic utility. Mol. Biol. Evol. 15: 1658-1673.

Mason-Gamer, R.J. (2001) Origin of North American species of Elymus (Poaceae: Triticeae) allotetraploids based on granule-bound starch synthase gene sequences. Systematic Botany 26: 757-768.

Mason-Gamer, R.J., N.L.Orme and C.M.Anderson (2002) Phylogenetic analysis of North American Elymus and the monogenomic Triticeae (Poaceae) using three chloroplast DNA data sets. Genome 45: 991-1002.

Mason-Gamer,R.J. (2004) Reticulate evolution, introgression, and intertribal gene capture in an allohexaploid grass. Systematic Biology 53: 25-37.

Mason-Gamer, R.J. (2005) The $\beta$-amylase genes of grasses and a phylogenetic analysis of the Triticeae (Poaceae). Am. J. Bot. 92: 1045-1058.

Mason-Gamer,R.J., M.M.Burns and M.Naum (2005) Polyploidy, introgression, and complex phylogenetic patterns within Elymus. Czech J. Genet. Plant Breed. 41: 21-26 (Special Issue).

Murai,K., X.Naiyu and K.Tsunewaki (1989) Studies on the origin of crop species by restriction endonuclease analysis of organellar
DNA: III. Chloroplast DNA and interspecific relationships in the genus Secale. Jpn. J. Genet. 64: 35-47.

Muramatsu,M. (1986) The vulgare super gene, $Q$ : its universality in durum wheat and its phenotypic effects in tetraploid and hexaploid wheats. Can. J. Genet. Cytol. 28: 30-41.

Nishikawa, T., B. Salomon, T. Komatsuda, R. von Bothmer and K.Kadowaki (2002) Molecular phylogeny of the genus Hordeum using three chloroplast DNA sequences. Genome 45: 1157-1166.

Ohta, S. (1991) Phylogenetic relationship of Aegilops mutica Boiss. with the diploid species of concerning Aegilops-Triticum complex, based on the new method of genome analysis using its Bchromosomes. Memoirs of the College of Agriculture, Kyoto University, Kyoto, Japan 137: pp. 1-116.

Peterson,G. and O.Seberg (1997) Phylogenetic analysis of the Triticeae (Poaceae) based on rpoA sequence data. Mol. Phylogenet. Evol. 7: 217-330.

Peterson, G. and O.Seberg (2003) Phylogenetic analyses of the diploid species of Hordeum (Poaceae) and a revised classification of the genus. Syst. Bot. 28: 293-306.

Peterson, G., O.Seberg, M.Yde and K.Berthelsen (2006) Phylogenetic relationships of Triticum and Aegilops and evidence for the origin of the A, B, and D genomes of common wheat (Triticum aestivum). Mol. Phylogenet. Evol. 39: 70-82.

Peterson, G. and O.Seberg (2008) Phylogenetic relationships of allotetraploid Hordelymus europaeus (L.) Harz (Poaceae: Triticeae). Plant Syst. Evol. 273: 87-95.

Peterson, G. and O.Seberg (2009) Stowaway MITEs in Hordeum (Poaceae): evolutionary history, ancestral elements and classification. Cladistics 25: 198-208.

Sakamura,T. (1918) Kurze Mitteilung uber die Chromosomenzhalen und die Verwandtshaftsverhältnisse der Triticum Arten. Bot. Mag. Tokyo 32: 151-154.

Sallares, R. and T.A.Brown (2004) Phylogenetic analysis of complete $5^{\prime}$ external transcribed spacers of the $18 \mathrm{~S}$ ribosomal RNA genes of diploid Aegilops and related species (Triticeae, Poaceae). Genetic Resources and Crop Evolution 51: 701-712.

Seberg,O. and S.Frederikson (2001) A phylogenetic analysis of the monogenomic Triticeae (Poaceae) based on morphology. Bot. J. Linn. Soc. 136: 75-97.

van Slageren,M.W. (1994) Wild wheats: a monograph of Aegilops L. and Amblyopyrum (Jaub. and Spach) Eig (Poaceae). Agricultural University, Wageningen \& International Center for Agricultural Research in Dry Areas, Aleppo, Syria.

Simons, KJ., J.P.Fellers, H.N.Trick, Z.Zhang, Y.-S.Tai, B.S.Gill and J.D.Faris (2006) Molecular characterization of the major wheat domestication gene $Q$. Genetics 172: 547-555.

Stebbins, G.L. (1956) Taxonomy and the evolution of genera with special reference to the family Gramineae. Evolution 10: 235-245.

Stein,N. (2007) Triticeae genomics: advances in sequence analysis of large genome cereal crops. Chrom. Res. 15: 21-31.

Sun, G., M.Pourkheirandish and T.Komatsuda (2009) Molecular evolution and phylogeny of the PRB2 gene in the genus Hordeum. Annals of Botany 103: 975-983.

Sun, G. and B.Salomon (2009) Molecular evolution and origin of tetraploid Elymus species. Breed. Sci. 59: 487-491.

Taketa, S., S. Amano, Y.Tsujino, T. Sato, D. Saisho, K. Kakeda, M.Nomura, T.Suzuki, T.Matsumoto, K.Sato et al. (2008) Barley grain with adhering hulls is controlled by an ERF family transcription factor gene regulating a lipid biosynthesis pathway. Proc. Natl. Acad. Sci. USA 105: 4062-4067.

Taketa,S., Y.Nakauchi and R.v.Bothmer (2009) Phylogeny of two 
tetraploid Hordeum species, H. secalinum and $H$. capense inferred from physical mapping of $5 \mathrm{~S}$ and $18 \mathrm{~S}-25 \mathrm{~S}$ rDNA. Breed. Sci. 59 589-594.

Terachi,T., Y.Ogihara and K.Tsunewaki (1984) The molecular basis of genetic diversity among cytoplasms of Triticum and Aegilops. III. Chloroplast genomes of the $\mathrm{M}$ and modified $\mathrm{M}$ genomecarrying species. Genetics 108: 681-695.

Terachi,T. and K. Tsunewaki (1992) The molecular basis of genetic diversity among cytoplasms of Triticum and Aegilops. VIII. Mitochondrial RFLP analysis using cloned genes as probes. Mol. Biol. Evol. 9: 917-931.

Waines, J.G., K.Hilu and H.Sharma (1979) Species formation in Aegilops and Triticum. In: Estes, J.R., R.J.Tyrl and J.N.Brunken (eds.) Grasses and Grasslands, Systematics and Ecology, University of Oklahoma Press, Norman, pp. 89-108.

Wang, R.R.-C., R.von Bothmer, J.Dvorak, G.Fedak I.Linde-Laursen and M.Muramatsu (1994) Genome symbols in the Triticeae. In: Wang, R.R.-C., K.B.Jensen and C.Jaussi (eds.) Proc. $2^{\text {nd }}$ Int. Triticeae Symp. Forage and Range Research Laboratory, U.S.D.A., Logan, Utah, USA, pp. 29-34.

Watson,L. and M.J.Dallwiz (1994) The Grass Genera of the World, 2nd edn. CAB International, Oxon, p.1081.

Yamane,K. and T.Kawahara (2005) Intra- and interspecific phylogenetic relationships among diploid Triticum-Aegilops species based on base pair substitutions, indels and microsatellites in chloroplast non-coding sequences. Am. J. Bot. 92: 1887-1898.

Yen,C. and J.L.Yang (2009) Historical review and prospect of taxonomy of tribe Triticeae Dumortier (Poaceae). Breed. Sci. 59: 513518

Zohary,D. and D.Imber (1963) Genetic dimorphism in fruit types in Aegilops speltoides. Heredity 18: 223-231. 